\title{
Effect of Black Soymilk Processing Conditions On Anthocyanins Content
}

\author{
Thiana C. F. Esteves ${ }^{1}$, Ilana Felberg ${ }^{2}$, Veronica. M. A. Calado ${ }^{1}$, \\ Mercedes C. Carrão-Panizzi ${ }^{3}$ \\ ${ }^{1}$ (Escola de Química/ Universidade Federal do Rio de Janeiro, Brazil) \\ ${ }_{2}^{2}$ (Embrapa Agroindústria de Alimentos, Brazil) \\ ${ }^{3}$ (Embrapa Trigo, Brazil)
}

\begin{abstract}
Black soybean has drawn the attention of researchers and consumers because of health issues. The reason is the presence of the well-known antioxidants compounds called anthocyanins, besides isoflavones. However, further technical and scientific information are needed about the characteristics and possibilities of utilization of black soybean to produce some of the most consumed soy foods in the West, such as soymilk and soy beverages. In the present work, five methods of obtaining soymilk from black soybeans were evaluated by checking the profile and total anthocyanins content in the final product. The identification and quantification of black soybean and black soymilk's anthocyanins were determined by high performance liquid chromatography (HPLC), showing that cyanidin-3-glucoside was the most abundant compound. The best processing method studied was the one with reuse of cooking water and use of milled black soybean seeds as raw material.
\end{abstract}

Keywords: Black soymilk, processing, anthocyanins

\section{Introduction}

Black soybeans (Glycine $\max$ L. Merril) have been used as a health food and herbal extract for hundreds of years in Oriental medicine as good for blood circulation, counteracting toxic effects, relieving kidney disease, and also having antiaging benefits [1]. More recent studies attribute their therapeutic effects to the presence of bioactive compounds, such as isoflavones, saponins and anthocyanins, these last ones only present in black seed coat varieties [2]. Black soybeans have shown to promote anti-diabetes activity [3], antiobesity [3], hypolipidemic [4], anti-inflammatory [5], and antimutagenic clinical functions [6], [7], among others. Because of these evidences, consumers are increasingly interested on black soybean consumption potential benefits, with a rapidly growing demand for derived products.

Anthocyanins are flavonoids, red or purple color, recognized as health-promoting functional ingredients because of their antioxidant capacity [8]. Its profiles and contents can differ among varieties being cyanidin-3-glucoside the most abundant anthocyanins in investigated cultivars [9], [10]. Anthocyanins can also be greatly degraded by thermal processing and, once soybean must be thermally processed prior to be consumed, preparation methods need to be evaluated [11], [12].

Soymilk is a liquid extract obtained by adequate processing, resulting in a product with similar appearance to cow milk but different in flavor and composition [13]. Oriental traditional soymilk is obtained by: soaking soybean, grinding in water, filtering to remove insoluble residues, and heating to reduce antinutrients and inactivate beany flavor producing enzymes [14]. Despite soy proven benefits its consumption is still low in Western countries. Many efforts have been done to eliminate the beany flavor in soymilk by using simple technologies like hot water blanching and grinding to effective reduce off-flavors compounds formation and, consequently, increase consumers acceptance [15].

Different from most used soybean variety, the yellow soybean, there is a lack of information about how soymilk processing methods can affect black soymilk quality, once excessive heat can destroy anthocyanins. To provide required information about black soybean anthocyanins behavior during processing, this study aimed at processing black soymilk using five different methods and to identify and quantify anthocyanins in the final product.

\section{Raw material}

\section{Material and methods}

For all experiment two black soybeans were used as raw material and the study was carried out in two independent stages. In the first stage, black soybean (Glycine max L. Merril) was purchased from a local market, and in the second, black soybean (Glycine max L. Merril) was obtained from the Soybean Breeding Program for Human Consumption of Brazilian Agricultural Research Corporation (EMBRAPA), harvested in 2013. 


\section{Processing methods}

A total of five soymilk obtaining methods were evaluated on how the processing steps could influence on anthocyanins maintenance. Three traditional methods were tested in the first stage and two recent methods tested in the second stage. For all processing methods studied, samples were taken just before and after the pasteurization step so this specific thermal treatment impacts could be evaluated on black soymilk final anthocyanins content. Black soymilk samples were lyophilized and stored at $-18^{\circ} \mathrm{C}$ for anthocyanins analysis.

\subsubsection{Stage 1}

Three methods conventionally used for producing yellow soybean milk were conducted using black soybean. The first method was the traditional Chinese one, which consisted of soaking black soybean seeds in cold water for 8-12 hours, draining, grinding in cold water (1:8 soy:water ratio), centrifuging and pasteurizing (95/98 ${ }^{\circ} \mathrm{C}$ for $10 \mathrm{~min}$ ) [16]. The second method differed from the first by grinding soaked soybeans with boiling water [17]. In the third, black soybean seeds were soaked in cold water for 8-12 hours, drained, cooked in alkali water $(0.25 \%$ sodium bicarbonate solution), drained again, grinded with boiling water, centrifuged and pasteurized $\left(95 / 98^{\circ} \mathrm{C}\right.$ for $\left.10 \mathrm{~min}\right)$ [18].

\subsubsection{Stage 2}

The methods tested in stage 2 differed from one another in the inclusion of a milling step, changing the initial state of the raw material (whole or milled seeds). Continuing the numerical sequence, the fourth method consisted of cooking black soybeans seeds in $80^{\circ} \mathrm{C}$ water for $10 \mathrm{~min}(1: 8$ soy:water ratio), followed by grinding (with the blanching water), centrifuging and pasteurizing $\left(95 / 98^{\circ} \mathrm{C}\right.$ for $10 \mathrm{~min}$ ) [19]. In order to evaluate the influence of surface contact on black soybean anthocyanins extraction, the use of milled black soybean seeds as raw material was tested. Therefore, in the fifth method, black soybeans were first milled in a Hammer Mill (Perten Laboratory Mill 3100) with $0.8 \mu \mathrm{m}$ sieve, and then processed as on the fourth method to obtain black soymilk.

\section{Anthocyanins extraction \\ 2.3.1 Stage 1}

Methanolic extracts of black soybean and black soymilk samples were obtained according to Santiago et al., 2010 [20]. One gram of each sample was extracted with $2 \mathrm{~mL}$ of methanol/formic acid (90:10) solution, submitted to sonication for $10 \mathrm{~min}$ and centrifuged at $3.000 \mathrm{RPM}$ for $10 \mathrm{~min}$ at $20^{\circ} \mathrm{C}$. The supernatant was transferred to a $10 \mathrm{~mL}$ volumetric flask and the precipitate was resubmitted to the over-written procedure until the supernatant lost its coloration. Samples were completed to $10 \mathrm{~mL}$ with extraction solution and filtered through a PTFE membrane CHROMAFIL Xtra - 45/25, pore size: $0.45 \mu \mathrm{M}$, filter- $\varnothing: 25 \mathrm{~mm}$ and stored in amber bottle at $-18^{\circ} \mathrm{C}$. Samples were taken in duplicate.

\subsubsection{Stage 2}

Specific methodology for extracting black soybeans anthocyanins was carried out according to Wang et al., (2014) [12], with modifications. One gram of each sample was extracted with a methanol/water/hydrochloric acid (60:39:1) solution in a water bath (IKA HEIZBAD HB-250) at $50^{\circ} \mathrm{C}$ for 1 hour, homogenizing every 10 minutes by vortexing for 5 seconds. After extraction, the mixture was centrifuged (SORVALL LEGEND Centrifuge XRT) at $12.000 \mathrm{RPM}$ for $10 \mathrm{~min}$ at $25^{\circ} \mathrm{C}$. The supernatant was completed to $50 \mathrm{~mL}$ (volumetric flask) with the extraction solution, filtered through a PTFE membrane CHROMAFIL Xtra - 45/25, pore size: $0.45 \mu \mathrm{M}$, filter- $\varnothing: 25 \mathrm{~mm}$ and stored in amber bottle at $-18^{\circ} \mathrm{C}$. Samples were taken in duplicate.

\section{Anthocyanins Analytical Method}

Chromatographic analysis was performed according to Santiago et al. (2010) [20], using a Waters® Alliance 2695 system equipped with a Waters ${ }^{\circledR} 2996$ photodiode array detector. Anthocyanins were separated on a Thermo ${ }^{\circ}$ Scientific C18 BDS $(100 \mathrm{~mm} \times 4.6 \mathrm{~mm} ; 2.4 \mu \mathrm{m})$ column, using a gradient of acetonitrile and $5 \%$ aqueous formic acid as mobile phase at $1 \mathrm{~mL} / \mathrm{min}$. Column temperature was set at $30^{\circ} \mathrm{C}$. Chromatograms were processed at $520 \mathrm{~nm}$, using Empower® software (Waters). Anthocyanins were quantified by external standardization [20].

\section{Results and Discussion}

Three anthocyanins were identified in both commercial and Embrapa's black soybean: delphinidin-3glucoside, cyanidin-3-glucoside and petunidin-3-glucoside, being the cyanidin-3-glucoside the majority anthocyanin (Figure 1). Koh et al. (2014) [10] which identified anthocyanins from two different black soybean varieties also found delphinidin-3-glucoside, cyanidin-3-glucoside and petunidin-3-glucoside as the three major anthocyanins. Zhang et al. (2011) [9] evaluated the composition of the seed coat of 60 Chinese black soybean 
and cyanidin-3-glucoside was the most abundant anthocyanin in all varieties. Differently from the soybean seeds profile, some black soymilk samples showed different profile because of the losses in anthocyanins content during processing.

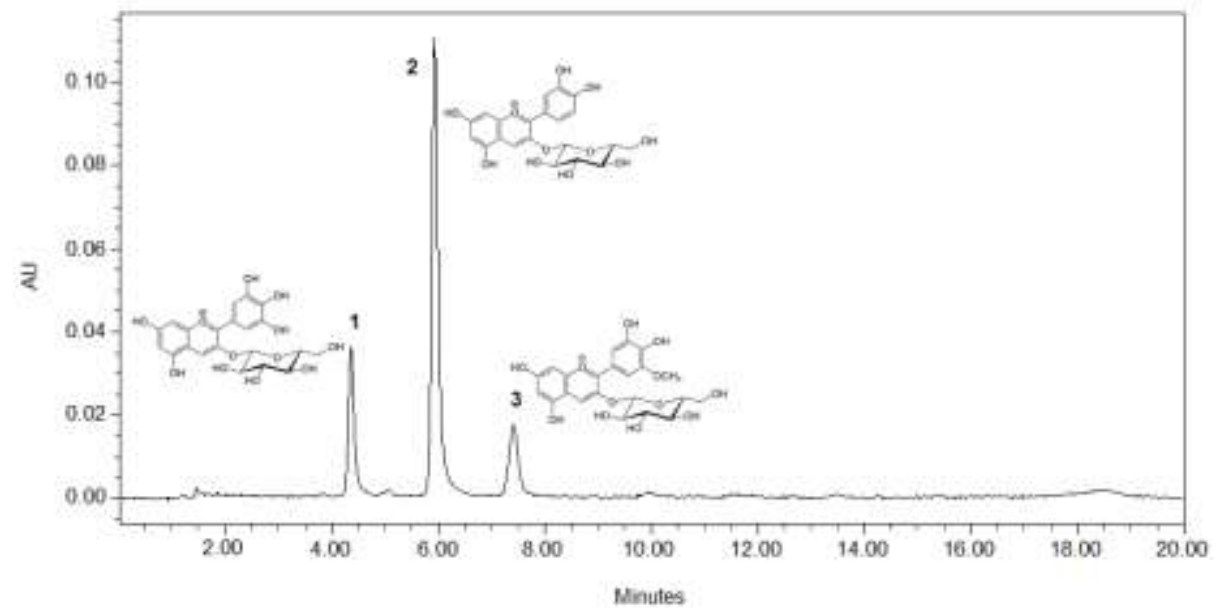

Figure 1: HPLC-PDA chromatogram of anthocyanin extract from black soybean. Peaks identification: 1: delfinidin-3-O-glucoside; 2: cyanidin-3-O-glucoside; 3: petunidin-3-O-glucoside.

\subsection{Stage 1}

The results of anthocyanins profile and content from black soybean and black soymilk obtained in the methods tested in stage 1 are presented in Table 1 . The first and third methods showed to be absolutely inadequate for black soymilk processing, with the complete degradation of anthocyanins. In the first method, cold grinding was not effective to extract anthocyanins from black soybean coat. On the other hand, in the third method, cooking favored anthocyanins migration, but draining steps resulted in total loss of these compounds. In Fig.2 is possible to observe through water color how cooking made anthocyanins extraction easier when compared to soaking step. In fact, according to Azmir et al. (2013) [21], the application of heat is the base of many bioactive compounds extraction techniques.

Second method showed greater anthocyanins content. Some losses happened during soaking, but the hot grinding favored anthocyanins extraction resulting in a black soymilk with about $50 \%$ of anthocyanins content preserved from the original seed (Black soymilk 2-B). For this sample, pasteurization showed to have a negative effect on anthocyanins stability (Black soymilk 2-A), reducing its content in almost a half part, and confirming the influence of heating exposure on anthocyanins degradation. In agreement to these findings, Sarkis et al. (2013) [22] evaluated the effect of heating on anthocyanin degradation during the processing of blueberry pulp and concluded that the magnitude and the duration of the heating process have a strong influence in anthocyanin stability.

Table 1: Profile and content of anthocyanins present in black soybean and black soymilk samples obtained from processing methods tested in stage 1 .

\begin{tabular}{|c|c|c|c|c|}
\hline \multirow[t]{2}{*}{ Samples $^{\S}$} & \multicolumn{4}{|c|}{ Anthocyanins (mg/100g, DB**) } \\
\hline & $\begin{array}{l}\text { Delphinidin-3- } \\
\text { glucoside }\end{array}$ & $\begin{array}{l}\text { Cyanidin-3- } \\
\text { glucoside }\end{array}$ & $\begin{array}{l}\text { Petunidin-3- } \\
\text { glucoside }\end{array}$ & Total \\
\hline Black soybean (local market) & 0.14 & 39.41 & 0.57 & 40.12 \\
\hline Black soymilk 1-B & $\mathrm{ND}^{*}$ & 0.36 & $\mathrm{ND}^{*}$ & 0.36 \\
\hline Black soymilk 1-A & ND* & 0.15 & ND* & 0.15 \\
\hline Black soymilk 2-B & ND* & 22.99 & ND* & 22.99 \\
\hline Black soymilk 2-A & $\mathrm{ND}^{*}$ & 12.89 & ND* & 12.89 \\
\hline Black soymilk 3-B & ND* & $\mathrm{ND}^{*}$ & ND* & $\mathrm{ND}^{*}$ \\
\hline Black soymilk 3-A & $\mathrm{ND}^{*}$ & $\mathrm{ND}^{*}$ & $\mathrm{ND}^{*}$ & ND* \\
\hline
\end{tabular}

ND*: not detected, lower value than instrument limit of detection. **DB: dry basis.

${ }^{\S}$ Soymilk resulted from the fifth processes studied. B: before pasteurization. A: After pasteurization. 


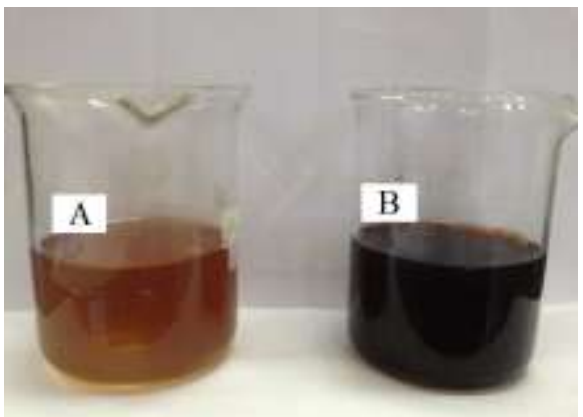

Figure 2: A: water resulted from soaking step of method 1; B: water resulted from cooking step in method 3.

\subsection{Stage 2}

The results of anthocyanins quantification in the samples studied are presented in Table 2. The use of milled seeds for obtaining black soymilk presented advantageous in relation to the use of whole seeds, confirming that an increase in the surface area/volume ratio of the food favored anthocyanins extraction from the seed to the soymilk. Although the influence of particle size had not been previously evaluated for black soymilk processing, Luthria et al. (2008) [23] found an increased extraction yield of phenolic compounds from parsley flakes due to a larger surface area per unit mass resultant of the greater accessibility of the analyte to the extraction solvent. It was also possible to verify greater loss of anthocyanins in the samples submitted to pasteurization thermal treatment, confirming the influence of temperatures exposure on the degradation of anthocyanins. Therefore, the black soymilk with the highest content of anthocyanins was obtained from milled black soybeans before pasteurization (Black soymilk 5-B), which maintained about $80 \%$ of anthocyanins content from the original seed (Figure 3).

Table 2: Profile and content of anthocyanins present in black soybean and black soymilk samples obtained from processing methods tested in stage 2 .

\begin{tabular}{|c|c|c|c|c|}
\hline \multirow{2}{*}{ Samples $^{\S}$} & \multicolumn{4}{|c|}{ Anthocyanins (mg/100g, DB**) } \\
\cline { 2 - 5 } & $\begin{array}{c}\text { Delphinidin-3- } \\
\text { glucoside }\end{array}$ & $\begin{array}{c}\text { Cyanidin-3- } \\
\text { glucoside }\end{array}$ & $\begin{array}{c}\text { Petunidin-3- } \\
\text { glucoside }\end{array}$ & Total \\
\hline Black soybean (Embrapa) & 16.74 & 42.39 & 6.45 & 65.58 \\
\hline Black soymilk 4-B & 4.38 & 36.63 & 4.40 & 45.41 \\
\hline Black soymilk 4-A & 1.93 & 23.34 & 2.66 & 27.92 \\
\hline Black soymilk 5-B & 8.12 & 40.01 & 5.81 & 53.94 \\
\hline Black soymilk 5-A & 3.86 & 38.82 & 4.76 & 47.44 \\
\hline
\end{tabular}

ND*: not detected, lower value than instrument limit of detection. **DB: dry basis.

${ }^{\S}$ Soymilk resulted from the fifth processes studied. B: before pasteurization. A: After pasteurization.

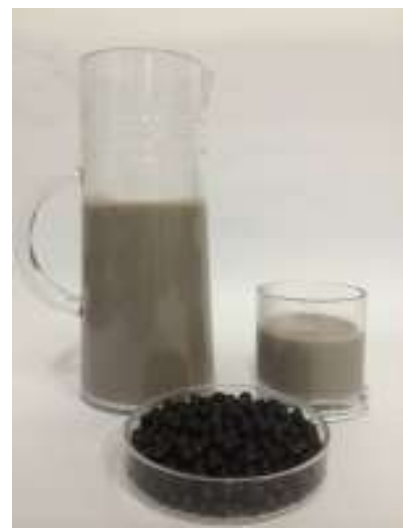

Figure 3: Blacksoymilk with greater preserved anthocyanins content

\section{Conclusions}

Processing methods involving draining after soaking or cooking steps were not suitable for obtaining black soymilk. The utilization of soaking and cooking water during grinding step was an essential procedure to reduce anthocyanins losses in the final product. The use of milled seeds instead of whole seeds was therefore also an important step in the process of obtaining a black soymilk rich in anthocyanins. New studies to define the best time/temperature processing conditions are in progress. 


\section{References}

[1]. B. Xu, and S. K. Chang, Antioxidant capacity of seed coat, dehulled bean, and whole black soybeans in relation to their distributions of total phenolics, phenolic acids, anthocyanins, and isoflavones. J Agric Food Chem, 56(18), 2008a, 8365-8373.

[2]. T. J. Ha, J. H. Lee, S.-O. Shin, S.-H. Shin, S.-I. Han, H.-T. Kim, J.-M. Ko, M.-H. Lee, and K.-Y. Park, Changes in anthocyanin and isoflavone concentrations in black seed-coated soybean at different planting locations. Journal of Crop Science and Biotechnology, 12(2), 2009, 79-86.

[3]. Y. Kanamoto, Y. Yamashita, F. Nanba, T. Yoshida, T. Tsuda, I. Fukuda, S. Nakamura-Tsuruta, and H. Ashida, A black soybean seed coat extract prevents obesity and glucose intolerance by up-regulating uncoupling proteins and down-regulating inflammatory cytokines in high-fat diet-fed mice. J Agric Food Chem, 59(16), 2011, 8985-8993.

[4]. K. Kim, K.-M. Lim, C.-W. Kim, H.-J. Shin, D.-B. Seo, S.-J. Lee, J.-Y. Noh, O.-N. Bae, S. Shin, and J.-H. Chung, Black soybean extract can attenuate thrombosis through inhibition of collagen-induced platelet activation. The Journal of Nutritional Biochemistry, 22(10), 2011, 964-970

[5]. R. Takahashi, R. Ohmori, C. Kiyose, Y. Momiyama, F. Ohsuzu, and K. Kondo, Antioxidant activities of black and yellow soybeans against low density lipoprotein oxidation. Journal of Agricultural and Food Chemistry, 53(11), 2005, 4578-4582.

[6]. M. Slavin, W. Kenworthy, and L. L. Yu, Antioxidant properties, phytochemical composition, and antiproliferative activity of Maryland-grown soybeans with colored seed coats. J Agric Food Chem, 57(23), 2009, 11174-11185.

[7]. Y. Zou, and S. K. Chang, Effect of black soybean extract on the suppression of the proliferation of human AGS gastric cancer cells via the induction of apoptosis. J Agric Food Chem, 59(9), 2011, 4597-4605.

[8]. K. Koh, J. E. Youn, and H. S. Kim, Identification of anthocyanins in black soybean (Glycine max (L.) Merr.) varieties. J Food Sci Technol, 51(2), 2014, 377-381.

[9]. R. F. Zhang, F. X. Zhang, M. W. Zhang, Z. C. Wei, C. Y. Yang, Y. Zhang, X. J. Tang, Y. Y. Deng, and J. W. Chi, Phenolic composition and antioxidant activity in seed coats of 60 Chinese black soybean (Glycine max L. Merr.) varieties. J Agric Food Chem, 59(11), 2011, 5935-5944.

[10]. K. Koh, J. E. Youn, and H. S. Kim, Identification of anthocyanins in black soybean (Glycine max (L.) Merr.) varieties. J Food Sci Technol, 51 (2), 2014, 377-81.

[11]. B. Xu, and S. K. Chang, Total phenolics, phenolic acids, isoflavones, and anthocyanins and antioxidant properties of yellow and black soybeans as affected by thermal processing. J Agric Food Chem, 56(16), 2008b, 7165-7175.

[12]. D. Wang, Y. Ma, C. Zhang, and X. Zhao, Thermal characterization of the anthocyanins from black soybean (Glycine max L.) exposed to thermogravimetry. LWT - Food Science and Technology, 55(2), 2014, 645-649.

[13]. F. H. Poliseli-Scopel, M. Hernández-Herrero, B. Guamis, and V. Ferragut, Comparison of ultra high pressure homogenization and conventional thermal treatments on the microbiological, physical and chemical quality of soymilk. LWT - Food Science and Technology, 46(1), 2012, 42-48.

[14]. Y. Tan, S. K. C. Chang, and Y. Zhang, Innovative Soaking and Grinding Methods and Cooking Affect the Retention of Isoflavones, Antioxidant and Antiproliferative Properties in Soymilk Prepared from Black Soybean. Journal of Food Science, 81(4), 2016, H1016-H1023.

[15]. Y. C. Lv, H. L. Song, X. Li, L. Wu, and S. T. Guo, Influence of blanching and grinding process with hot water on beany and nonbeany flavor in soymilk. J Food Sci, 76(1), 2011, S20-25.

[16]. K. Tanteeratarm, A.I. Nelson, and L.S. Wei, Manufacturing of bland soymilk, in: WILLIAMS, S.W., Soybean processing for food uses. (Urbana: INTSOY, 1999) $154-164$

[17]. V. D. T. Benassi, F. Yamashita, and S. H. Prudencio, A statistical approach to define some tofu processing conditions. Food Science and Technology (Campinas), 31, 2011, 897-904.

[18]. Felberg, R. Antoniassi, R. Deliza, Manual de produção de extrato de soja para agroindústria de pequeno porte ( Rio de Janeiro: Embrapa Agroindústria de Alimentos, 2005).

[19]. M. L. De Moraes Filho, S. S. Hirozawa, S. H. Prudencio, E. I. Ida, S. Garcia, Petit Suisse from black soybean: bioactive compounds and antioxidant properties during development process. Int J Food Sci Nutr, 65 (4), 2014, 470-475.

[20]. M. C. P. A. Santiago, A.C.M.S. Gouvêa, R. L. O. Godoy, J. Oiano-Neto, S. Pacheco, J. S. Rosa, Adaptação de um método por cromatografia líquida de alta eficiência para análise de antocianinas em suco de açaí (Euterpe oleraceae Mart.) (Rio de Janeiro: Embrapa Agroindústria de Alimentos, 2010).

[21]. J. Azmir, I. S. M. Zaidul, M. M. Rahman, K. M. Sharif, A. Mohamed, F. Sahena, M. H. A. Jahurul, K. Ghafoor, N. A. N. Norulaini, and A. K. M. Omar, Techniques for extraction of bioactive compounds from plant materials: A review. Journal of Food Engineering, 117(4), 2013, 426-436.

[22]. J. R. Sarkis, D. P. Jaeschke, I. C. Tessaro, L. D. F. Marczak, Effects of ohmic and conventional heating on anthocyanin degradation during the processing of blueberry pulp. LWT - Food Science and Technology, 51, 2013, 79-85.

[23]. D. L. Luthria, Influence of experimental conditions on the extraction of phenolic compounds from parsley (Petroselinum crispum) flakes using a pressurized liquid extractor. Food Chemistry, 107(2), 2008, 745-752. 